\title{
Clinical and molecular review of atypical congenital adrenal hyperplasia
}

\author{
Taninee Sahakitrungruang, \\ MD
}

Division of Pediatric Endocrinology, Department of Pediatrics, Faculty of Medicine, Chulalongkorn University, Bangkok, Thailand

\begin{abstract}
Congenital adrenal hyperplasia (CAH) is one of the most common inherited metabolic disorders. It comprises a group of autosomal recessive disorders caused by the mutations in the genes encoding for steroidogenic enzymes that involved cortisol synthesis. More than $90 \%$ of cases are caused by a defect in the enzyme 21-hydroxylase. Four other enzyme deficiencies (cholesterol side-chain cleavage,

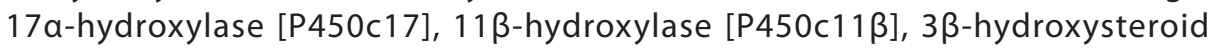
dehydrogenase) in the steroid biosynthesis pathway, along with one cholesterol transport protein defect (steroidogenic acute regulatory protein), and one electrontransfer protein (P450 oxidoreductase) account for the remaining cases. The clinical symptoms of the different forms of $\mathrm{CAH}$ result from the particular hormones that are deficient and those that are produced in excess. A characteristic feature of $\mathrm{CAH}$ is genital ambiguity or disordered sex development, and most variants are associated with glucocorticoid deficiency. However, in the rare forms of CAH other than 21-hydroxylase deficiency so-called "atypical CAH", the clinical and hormonal phenotypes can be more complicated, and are not well recognized. This review will focus on the atypical forms of $\mathrm{CAH}$, including the genetic analyses, and phenotypic correlates.
\end{abstract}

Keywords: Congenital adrenal hyperplasia, Rare disease, Genotypes, Phenotypes

\section{Introduction}

Congenital adrenal hyperplasia (CAH) is one of the most common inherited metabolic disorders and is associated with significant morbidity and mortality in affected children. It comprises a group of autosomal recessive disorders caused by the mutations in the genes encoding for steroidogenic enzymes that involved cortisol synthesis. Impaired cortisol secretion results in hypersecretion of corticotropin-releasing hormone and adrenocorticotropic hormone (ACTH) and consequent hyperplasia of the adrenal glands. The clinical phenotypes and biochemical characteristics depend on the specific enzymatic defect. There is a broad clinical spectrum of this disorder. In most forms of CAH, it can be fatal if not diagnosed early in infancy ${ }^{1)}$.

The adrenal cortex is the production site for three classes of steroid hormones: mineralocorticoids, glucocorticoids, and sex hormones. The cortex is divided into three zones by different cellular arrangements, each one functionally distinct due to the enzymes required for different hormone production. The outer zona glomerulosa does not express 17 -hydroxylase $\left.(\mathrm{P} 450 \mathrm{c} 17)^{2}\right)$ and hence produces 17 -deoxysteroids leading to aldosterone (the most potent mineralocorticoid), and is regulated primarily by the renin/angiotensin system. The middle zona fasciculata expresses the $17 \alpha$-hydroxylase activity but very little of the 17,20-lyase activity of P450c17, and hence produces 21-carbon, 17-hydroxysteroids, leading to cortisol under the influence of ACTH. The inner zona reticularis expresses both the 17a-hydroxylase and 17,20-lyase activities of P450c17, and hence produce the 19-carbon
Address for correspondence: Taninee Sahakitrungruang, MD Division of Pediatric Endocrinology, Department of Pediatrics, Faculty of Medicine, Chulalongkorn University, Bangkok 10330, Thailand

Tel: +66-2-256-4996

Fax: +66-2-256-4911

E-mail:Taninee.P@chula.ac.th 
17-hydroxy steroid dehydroepiandrosterone (DHEA), the precursor of sex steroids ${ }^{1,3)}$.

ACTH regulates steroidogenesis (chronic regulation) by inducing the transcription of genes encoding various steroidogenic enzymes, but acute regulation is at the level of cholesterol access to cholesterol side-chain cleavage (P450scc). The steroidogenic acute regulatory protein (StAR) facilitates the movement of cholesterol into mitochondria, where it is converted to pregnenolone by $\mathrm{P} 450 \mathrm{scc}^{4)}$. Simplified diagram of adrenal steroidogenic pathways was shown in Fig. 1.

There have been nationwide newborn screening programs for $\mathrm{CAH}$ in only a few countries in Asia, although the recent pilot study suggested the high prevalence of CAH in Southeast Asian countries $^{5,6)}$. More than $90 \%$ of cases are caused by a defect in the enzyme 21-hydroxylase (P450c21). Four other enzyme deficiencies in the steroid biosynthesis pathway (P450scc, P450c17, 11 $\beta$-hydroxylase [P450c11 $\beta$ ], 3 $\beta$-hydroxysteroid dehydrogenase [ $3 \beta \mathrm{HSD}]$ ), along with one cholesterol transport protein defect (StAR), and one electron-transfer protein (P450 oxidoreductase; POR) account for the remaining cases. In these uncommon forms of $\mathrm{CAH}$, the clinical and hormonal phenotypes can be complicated, and are not widely recognized by endocrinologists or pediatricians.

The clinical symptoms of the different forms of $\mathrm{CAH}$ result from the particular hormones that are deficient and those that are produced in excess. A characteristic feature of CAH is genital ambiguity or disordered sex development (DSD), and all variants are associated with glucocorticoid deficiency. Each variant of $\mathrm{CAH}$ is summarized in Table 1 . In this review, we focus on the molecular genetic basis of the variant forms of CAH other than 21-hydroxylase so-called "atypical CAH", including the genetic analysis, and phenotypic correlates.

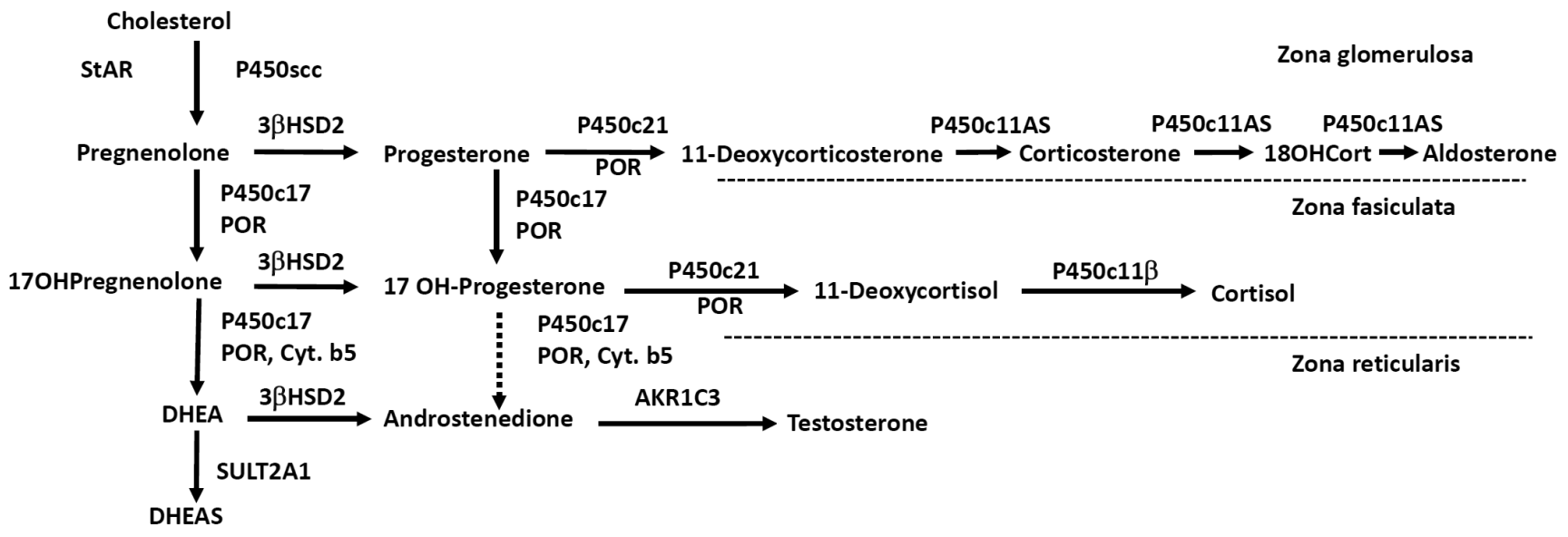

Fig. 1. Simplified scheme of adrenal steroidogenesis. AKR, aldo-keto reductase; Cyt.b5, cytochrome b5; P450scc, cholesterol side-chain cleavage enzyme; P450c17,

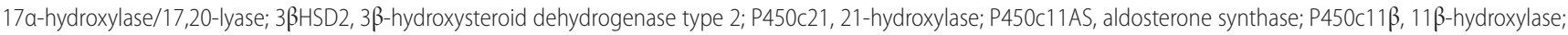
POR, P450 oxidoreductase; StAR, steroidogenic acute regulatory protein; SULT2A1, sulfotransferase; 180HCort, 18-hydroxycorticosterone.

Table 1. Characteristics of different forms of congenital adrenal hyperplasia (CAH)

\begin{tabular}{|c|c|c|c|c|c|c|}
\hline Characteristic & $\begin{array}{l}\text { 21-Hydroxylase } \\
\text { deficiency }\end{array}$ & $\begin{array}{c}\text { 11ß-Hydroxylase } \\
\text { deficiency }\end{array}$ & $\begin{array}{l}\text { 17a-Hydroxylase } \\
\text { deficiency }\end{array}$ & $\begin{array}{c}\text { 3ß-Hydroxysteroid } \\
\text { dehydrogenase } \\
\text { deficiency }\end{array}$ & $\begin{array}{l}\text { Congenital lipoid } \\
\text { adrenal hyperplasia }\end{array}$ & $\begin{array}{c}\text { P450 } \\
\text { Oxidoreductase } \\
\text { deficiency }\end{array}$ \\
\hline Gene involved & CYP21A2 & CYP11B1 & CYP17A1 & HSD3B2 & StAR/CYP11A1 & $P O R$ \\
\hline Chromosome location & $6 p 21.3$ & $8 q 24.3$ & $10 q 24.3$ & 1p13.1 & $8 p 11.2 / 15 q 24.1$ & $7 q 11.2$ \\
\hline Ambiguous genitalia & Yes in XX & Yes in XX & Yes in $X Y$ & Yes in $X Y, \pm$ in $X X$ & Yes in $X Y$ & $\begin{array}{l}\text { Yes in both } X X \\
\text { and } X Y\end{array}$ \\
\hline Adrenal crisis & Yes & Rare & No & Yes & Yes & Rare \\
\hline Serum cortisol & $\downarrow$ & $\downarrow$ & $\downarrow$ & $\downarrow$ & $\downarrow$ & Normal/ $\downarrow$ \\
\hline Mineralocorticoid & $\downarrow$ & $\uparrow$ & $\uparrow$ & $\downarrow$ & $\downarrow$ & Normal \\
\hline Androgens & $\uparrow$ & $\uparrow$ & $\downarrow$ & $\downarrow$ & $\downarrow$ & $\downarrow$ \\
\hline Serum Na & $\downarrow$ & $\uparrow$ & $\uparrow$ & $\downarrow$ & $\downarrow$ & Normal/ $\downarrow$ \\
\hline Serum K & $\uparrow$ & $\downarrow$ & $\downarrow$ & $\uparrow$ & $\uparrow$ & Normal \\
\hline Metabolite elevated & $170 \mathrm{HP}$ & DOC, 11-deoxycortisol & DOC, corticosterone & DHEA, 17OHPreg & None & $170 \mathrm{PP}$ \\
\hline
\end{tabular}

17OHP, 17-hydroxyprogesterone; DOC, deoxycorticosterone; DHEA, dehydroepiandrosterone; 17OHPreg, 17-hydroxypregnenolone. 


\section{Congenital lipoid adrenal hyperplasia (lipoid CAH)}

Congenital lipoid adrenal hyperplasia is the most severe form of $\mathrm{CAH}$ in which the synthesis of all adrenal and gonadal steroid hormones is impaired and leads to the accumulation of cholesterol esters ${ }^{7,8)}$. The true incidence of lipoid CAH is unknown, but it is clearly much higher in Japanese, Korean and Palestinian population. Patients with classic lipoid CAH usually present with adrenal failure and salt wasting, beginning within the first few months of life, and have female external genitalia irrespective of genetic sex ${ }^{1)}$.

Early clinical hormonal studies and incubations of affected tissue in vitro with various precursors identified a defect in the conversion of cholesterol to pregnenolone, so that the disorder was initially called "20,22 desmolase deficiency" as it was thought to result from a defect in the enzyme system converting cholesterol to pregnenolone; this enzyme was later identified as mitochondrial P450scc. However, in 1995 it was found that lipoid CAH results from mutations in the gene encoding the StAR ${ }^{7}$. StAR facilitates the movement of cholesterol into mitochondria, where it is converted to pregnenolone by P450 $\mathrm{scc}^{4)}$. StAR is expressed in the adrenals and gonads but not in the placenta" ${ }^{9)}$. Because placental production of progesterone is essential for the maintenance of human pregnancy, mutations in P450scc were thought to be incompatible with term gestation. Nevertheless, beginning in 2001 several patients with defects in CYP11A1 gene causing P450scc deficiency have been reported ${ }^{10-17)}$. Most of these cases were caused by severe lossof function mutations and presented with severe, early onset adrenal failure and complete phenotypic $46, \mathrm{XY}$ sex reversal in genetic males ${ }^{14)}$, although patients with late-onset nonclassic disease have been reported ${ }^{15-18)}$. Thus, both of the defects of StAR and P450scc are now considered to be responsible for lipoid CAH, but most lipoid CAH may be caused by the mutations in the StAR gene.

More than 40 StAR mutations causing classic lipoid CAH have been described, but very few partial loss-of-function mutations have been reported ${ }^{19-21)}$. The mutations are present in all exons. The mutations in intronic region are also found. The mutations causing premature translational termination or altering of the StAR reading frame are common, and they substantially alter the structure of the StAR protein. All missense mutations are found in the carboxy-terminal $40 \%$ of the amino acid StAR protein ${ }^{22)}$. The Q258X mutation in exon 7 is very common in Japanese and Korean ${ }^{23,24)}$. In Japanese this mutation is identified in $62 \%$ of the alleles and in over $80 \%$ of the patients. Other genetic clusters are found among Palestinian Arabs, most of whom carry the mutation R182L ${ }^{8}$; in eastern Saudi Arabia, carrying $\mathrm{R} 182 \mathrm{H}^{25}$; and in parts of Switzerland, carrying the mutation $\mathrm{L} 260 \mathrm{P}^{26)}$.

Nonclassic lipoid CAH is a recently recognized disorder caused by StAR mutations that retain partial activity ${ }^{19)}$. Affected individuals can present with later onset of adrenal insufficiency resembling nonautoimmune Addison disease with only mildly disordered sexual development or normal development with hypergonadotropic hypogonadism ${ }^{19-21)}$. We recently reported four patients with nonclassic/atypical lipoid CAH and demonstrated that there is a broad clinical spectrum of StAR mutations ${ }^{21}$. While there is some variability in these biochemical assays, it seems that $10 \%-20 \%$ activity will dramatically alter the classic phenotype ${ }^{21)}$. The R188C mutation was found in patients from Thailand, Canada, Jordan, India and Pakistan ${ }^{19-21)}$, suggesting a recurrent mutation. To date, most patients with non-classic lipoid CAH carry R188C, although other mutations can cause this phenotyp $\mathrm{e}^{19-21)}$.

\section{3ßHSD deficiency}

$3 \beta \mathrm{HSD}$ or $\Delta 5 \rightarrow \Delta 4$-isomerase is a $42 \mathrm{kDa}$ microsomal enzyme catalyzes steroidogenic reactions: the conversion of the hydroxyl group to a keto group on carbon 3 and the isomerization of $\Delta 5$ steroids precursors into $\Delta 4$ ketosteroids $^{27)}$. Therefore, $3 \beta \mathrm{HSD}$ is responsible for the conversion of pregnenolone to progesterone, $17 a$-hydroxypregnenolone (17OHPreg) to 17 $\alpha$-hydroxyprogesterone (17OHP), DHEA to androstenedione, and androstenediol to testosterone. Thus, $3 \beta \mathrm{HSD}$ is an essential enzyme for biosynthesis of all classes of active steroid hormones including aldosterone, and cortisol in adrenal cortex, and sex steroids in adrenals and gonads.

In humans, there are two closely linked genes HSD3B1 and $H S D 3 B 2$ located on chromosome 1 encoded two isoforms of $3 \beta \mathrm{HSD}^{28)}$. The type 1 enzyme (3ßHSD1) encoded by HSD3B1 is primarily expressed in placenta, mammary gland, liver, skin and some other tissues ${ }^{29} .3 \beta H S D 1$ is required for placental progesterone synthesis during pregnancy. Mutations in HSD $3 B 1$ gene have never been described, presumably because these would cause a spontaneous abortion due to lack of placental progesterone synthesis. In contrast, the type 2 enzyme (3ßHSD2) encoded by $H S D 3 B 2$ gene is predominantly expressed in the adrenals and gonads ${ }^{29)}$. Defects in HSD3B2 gene causes 3 $3 \mathrm{HSD}$ deficiency, which is a rare form of $\mathrm{CAH}$, and can be fatal if not diagnosed early in infancy ${ }^{30)}$.

The clinical spectrum of $3 \beta \mathrm{HSD}$ deficiency ranges from saltwasting to non-salt-wasting forms. In its classic form, $3 \beta \mathrm{HSD}$ deficiency causes various degrees of salt-wasting in both sexes. In genetic males, $3 \beta \mathrm{HSD}$ deficiency in the testes impairs testosterone biosynthesis from early fetal life, so that these males have undervirilization of the external genitalia, and usually present at birth with severe hypospadias and micropenis. By contrast, genetic females have normal female genitalia or slightly virilized genitalia such as isolated clitoromegaly, because the fetal adrenal overproduces large amounts of DHEA, which can be converted to testosterone by extraadrenal $3 \beta H S D 1^{1,31)}$. In this way, the presence of peripheral $3 \beta \mathrm{HSD} 1$ activity often complicates the hormonal diagnosis of this disorder in that very high $17 \mathrm{OHPreg}$ levels can be converted extra-adrenally to $17 \mathrm{OHP}$ confuses the diagnosis as 21-hydroxylase deficiency ${ }^{31}$, 32) 
Mild forms of 3 3 HSD deficiency cause premature acne, premature pubarche, and growth acceleration in children ${ }^{33)}$ and a late onset variant manifesting with hirsutism, menstrual disorder, and polycystic ovaries in young women ${ }^{34,35)}$. The newly proposed hormonal criteria for diagnosis for $3 \beta \mathrm{HSD}$ deficiency were elevated basal and ACTH-stimulated 17OHPreg and 17 OHPreg to cortisol ratios, typically exceed 10 standard deviations above the mean ${ }^{36)}$. These criteria were revised based on genotype-proven patients.

To date approximately 40 mutations have been identified in the HSD3B2 gene in patients suffering from classical 33HSD deficiency. In most cases, the functional consequences of $H S D 3 B 2$ mutations are in close agreement with the severity of the clinical manifestation. However, the in vitro 33HSD activities alone cannot be used to predict the degree of male undervirilization ${ }^{31)}$.

\section{P450c11 $\beta$ deficiency}

$11 \beta$-hydroxylase deficiency (11OHD) accounts for about $5 \%-8 \%$ of CAH in people of European ancestry but accounts for about $15 \%$ of cases in both Muslim and Jewish Middle Eastern populations ${ }^{1)}$. P $450 \mathrm{c} 11 \beta$ catalyses conversion of 11-deoxycortisol to cortisol, representing the final step in cortisol biosynthesis. The enzyme also catalyses the monooxygenase reaction converting 11-deoxycorticosterone (DOC) to corticosterone. Thus, deficient P450c11 $\beta$ activity results in decreased cortisol secretion and accumulation of 11-deoxycortisol and the mineralocorticoid precursor DOC. Thus, patients can subsequently suffer from significant hypertension, a hallmark feature of this $\mathrm{CAH}$ variant. Accumulated precursors are shunted into the androgen synthesis pathway, leading to hyperandrogenism. Classic 11 OHD most commonly results in 46,XX DSD with severe virilization of the external genitalia, and precocious pseudopuberty in both sexes. Newborns may also have elevated concentrations of 17OHP, which accumulates two steps behind the enzymatic block, so that $\mathrm{P} 450 \mathrm{c} 11 \beta$ deficiency may be detected in newborn screening for P450c21 deficiency ${ }^{37 \text {. }}$. The diagnosis is established by elevated basal concentrations of DOC and 11-deoxycortisol, which hyperrespond to cosyntropin. $11 \mathrm{OHD}$ is caused by mutations in the CYP11B1 gene. At present, over 50 CYP11B1-inactivating mutations are described. Most are missense and nonsense mutations, but splice-site mutations, small deletions, small insertions, and complex rearrangements have also been detected ${ }^{38-40)}$. The vast majority of mutations are associated with classic 11OHD, and only a few mutations causing nonclassic $11 \mathrm{OHD}$ have been described in otherwise asymptomatic women with hirsutism, and menstrual irregularities ${ }^{41,42)}$.

Generally, the CYP11B1 gene is specifically amplified avoiding simultaneous amplification of homologous CYP11B2 sequences. In the majority of cases, molecular genetic analysis is not difficult. However, special cases are reported, such as an unequal crossing-over between the CYP11B2 and the CYP11B1 genes as a cause of $11 \mathrm{OHD}^{43)}$.

\section{P450c17 deficiency}

$\mathrm{P} 450 \mathrm{c} 17$ is the single microsomal cytochrome P450 enzyme that catalyzes both the $17 \alpha$-hydroxylation required to produce the 17 hydroxy 21-carbon precursors of cortisol, 17OHPreg and 17OHP, and the 17,20-lyase activity needed to produce 19-carbon precursors of sex steroids ${ }^{44)}$. P450c17 is encoded by CYP17A1 gene, consisting of eight exons and located on chromosome 10q24.3 ${ }^{45)}$. CYP17A1 mutations cause P450c17 deficiency, a rare form of CAH characterized by sexual infantilism, 46,XY sex reversal, hypertension and high ratios of $\mathrm{C} 21$ to $\mathrm{C} 19$ steroids. The lack of P450c17 activity disrupts cortisol secretion, driving the compensatory overproduction of a glucocorticoid, corticosterone, and a mineralocorticoid, deoxycorticosterone, causing hypertension and hypokalemia ${ }^{1,46}$. Rare patients may also have isolated 17,20 lyase deficiency, characterized by low $\mathrm{C} 19$ steroids with normal cortisol ${ }^{47,48}$.

Over 70 CYP17A1-inactivating mutations have been identified. There is no evidence of a hot spot in most large populations. Therefore, sequencing of the entire coding region is usually necessary. Exceptions have been described in the some population, where mutations appear recurrently (1) a duplication of four nucleotides causing a frameshift is found among descendents of Dutch Frieslanders; (2) in-frame deletion of residues 487-489 is found throughout Southeast Asia; (3) a deletion of phenylalanine at position 53 or 54 ; and (4) the common W406R and R362C mutations, found among Brazilians of Spanish and Portuguese ancestry, respectively ${ }^{1)}$.

Mutations underlying isolated 17,20 lyase deficiency result in amino acid substitutions located within the redox-partner binding site of $\mathrm{P} 450 \mathrm{c} 17$, thereby disrupting the electron transfer from POR to P450c17 specifically for the conversion of 17OHPreg to DHEA ${ }^{47,48}$.

\section{POR deficiency}

POR deficiency is a unique and newly recognized form of $\mathrm{CAH}$, biochemically manifesting with apparent combined P450c17 and P450c21 deficiency. POR transfers electrons from reduced nicotinamide adenine dinucleotide phosphate (NADPH) to all microsomal (type II) cytochrome P450 enzymes, including three steroidogenic enzymes: P450c17 (17a-hydroxylase/17,20 lyase), P450c21 (21-hydroxylase), and P450aro (aromatase) ${ }^{1}$. Although disruption of the POR gene in mice causes gross disorders of embryogenesis and embryonic lethality, in 2004 Fluck et al. ${ }^{49)}$ reported POR mutations in three children with ambiguous genitalia and skeletal malformations (Antley-Bixler syndrome, ABS) and in a phenotypically normal adult woman with primary amenorrhea and polycystic ovaries. The majority of patients with POR deficiency described to date have also had the ABS phenotype, characterized by craniosynostosis, radioulnar or radiohumeral synostosis, 
bowed femora, and other variable skeletal disorders ${ }^{1,50)}$. POR deficiency can cause ambiguous genitalia in both sexes. 46,XY males are typically undervirilized because decreased 17,20-lyase activity reduces androgen synthesis. 46,XX females are frequently virilized at birth, but this virilization is not progressive postnatally. There are two possible mechanisms for this virilization. First, because placental aromatase (P450aro) requires POR, a defect in this placental aromatase activity, either from mutation of POR or P450aro itself, will permit large amounts of fetal C19 steroids to enter and virilize the mother and the female fetus. Second, it appears to involve the "backdoor pathway" to fetal androgen production, in which 21 -carbon steroid precursors are $5 a$-reduced and ultimately converted to dihydrotestosterone, bypassing the conventional precursors androstenedione and testosterone ${ }^{1,50)}$.

The human $P O R$ gene consists of 16 exons, spanning approximately $70 \mathrm{~kb}$ on chromosome $7 \mathrm{q} 11.2$. The overall incidence of POR deficiency in the general population remains unclear. However, over 50 POR mutations have now been described, suggesting that this disorder may be relatively common. There is the great variability in the clinical and hormonal findings in POR deficiency. Some patients with milder POR mutations do not have ABS, and the steroidogenic defect may present as hypogonadism and/or infertility ${ }^{49-52)}$. Two mutations are especially common: A287P, the predominant mutation in patients of European ancestry, and $\mathrm{R} 457 \mathrm{H}$, the predominant mutation in patients of Japanese ancestry ${ }^{53-55)}$. The genotype-phenotype correlation is not fully established yet ${ }^{55,56)}$, and future studies are needed.

\section{Conclusions}

There is a broad spectrum of the clinical and hormonal phenotypes of $\mathrm{CAH}$ depending on the specific enzymatic defect. The diagnosis remains a challenge in patients with atypical forms of $\mathrm{CAH}$ and requires thorough clinical and hormonal work-up. Lifelong treatment with steroids is required for most patients. Confirmation of the diagnosis by genetic analysis is of clinical importance.

\section{Conflict of interest}

No potential conflict of interest relevant to this article was reported.

\section{Acknowledgments}

The author is grateful to Drs. Walter L. Miller (University of California, San Francisco, CA, USA) and Vorasuk Shotelersuk (Chulalongkorn University, Bangkok, Thailand) for their excellent mentorship. T.S. was supported by Ratchadapiseksompotch funds from Faculty of Medicine, Chulalongkorn University, and the Thailand Research Fund.

\section{References}

1. Miller WL, Auchus RJ. The molecular biology, biochemistry, and physiology of human steroidogenesis and its disorders. Endocr Rev 2011;32:81-151.

2. Suzuki T, Sasano H, Takeyama J, Kaneko C, Freije WA, Carr $\mathrm{BR}$, et al. Developmental changes in steroidogenic enzymes in human postnatal adrenal cortex: immunohistochemical studies. Clin Endocrinol (Oxf) 2000;53:739-47.

3. Miller WL. Minireview: regulation of steroidogenesis by electron transfer. Endocrinology 2005;146:2544-50.

4. Stocco DM, Clark BJ. Regulation of the acute production of steroids in steroidogenic cells. Endocr Rev 1996;17:221-44.

5. Janejai N, Krasao P, Phansang J, Pankarnjanato R, Charoensiriwatana W. Congenital adrenal hyperplasia: should nationwide screening be implemented in Thailand? Southeast Asian J Trop Med Public Health 2003;34 Suppl 3:170-3.

6. Somboonnithiphol K, Panamonta O, Kiatchoosakun P, Jirapradittha J, Panamonta M, Lumbiganon P. Newborn screening for congenital adrenal hyperplasia in Srinagarind Hospital, Khon Kaen University, Thailand. Asian Biomed 2011;5:855-9.

7. Lin D, Sugawara T, Strauss JF 3rd, Clark BJ, Stocco DM, Saenger P, et al. Role of steroidogenic acute regulatory protein in adrenal and gonadal steroidogenesis. Science 1995;267:1828-31.

8. Bose HS, Sugawara T, Strauss JF 3rd, Miller WL; International Congenital Lipoid Adrenal Hyperplasia Consortium. The pathophysiology and genetics of congenital lipoid adrenal hyperplasia. N Engl J Med 1996;335:1870-8.

9. Bose HS, Whittal RM, Baldwin MA, Miller WL. The active form of the steroidogenic acute regulatory protein, StAR, appears to be a molten globule. Proc Natl Acad Sci U S A 1999;96:7250-5.

10. Tajima T, Fujieda K, Kouda N, Nakae J, Miller WL. Heterozygous mutation in the cholesterol side chain cleavage enzyme (p450scc) gene in a patient with 46,XY sex reversal and adrenal insufficiency. J Clin Endocrinol Metab 2001;86:3820-5.

11. Katsumata N, Ohtake M, Hojo T, Ogawa E, Hara T, Sato $\mathrm{N}$, et al. Compound heterozygous mutations in the cholesterol side-chain cleavage enzyme gene (CYP11A) cause congenital adrenal insufficiency in humans. J Clin Endocrinol Metab 2002;87:3808-13.

12. Hiort O, Holterhus PM, Werner R, Marschke C, Hoppe U, Partsch CJ, et al. Homozygous disruption of P450 sidechain cleavage (CYP11A1) is associated with prematurity, complete 46,XY sex reversal, and severe adrenal failure. J Clin Endocrinol Metab 2005;90:538-41.

13. al Kandari H, Katsumata N, Alexander S, Rasoul MA. Homozygous mutation of P450 side-chain cleavage enzyme gene (CYP11A1) in 46, XY patient with adrenal insufficiency, complete sex reversal, and agenesis of corpus 
callosum. J Clin Endocrinol Metab 2006;91:2821-6.

14. Kim CJ, Lin L, Huang N, Quigley CA, AvRuskin TW, Achermann JC, et al. Severe combined adrenal and gonadal deficiency caused by novel mutations in the cholesterol side chain cleavage enzyme, P450scc. J Clin Endocrinol Metab 2008;93:696-702.

15. Rubtsov P, Karmanov M, Sverdlova P, Spirin P, Tiulpakov A. A novel homozygous mutation in CYP11A1 gene is associated with late-onset adrenal insufficiency and hypospadias in a 46,XY patient. J Clin Endocrinol Metab 2009;94:936-9.

16. Sahakitrungruang T, Tee MK, Blackett PR, Miller WL. Partial defect in the cholesterol side-chain cleavage enzyme P450scc (CYP11A1) resembling nonclassic congenital lipoid adrenal hyperplasia. J Clin Endocrinol Metab 2011;96:792-8.

17. Tee MK, Abramsohn M, Loewenthal N, Harris M, Siwach S, Kaplinsky A, et al. Varied clinical presentations of seven patients with mutations in CYP11A1 encoding the cholesterol side-chain cleavage enzyme, P450scc. J Clin Endocrinol Metab 2013;98:713-20.

18. Parajes S, Kamrath C, Rose IT, Taylor AE, Mooij CF, Dhir V, et al. A novel entity of clinically isolated adrenal insufficiency caused by a partially inactivating mutation of the gene encoding for P450 side chain cleavage enzyme (CYP11A1). J Clin Endocrinol Metab 2011;96:E1798-806.

19. Baker BY, Lin L, Kim CJ, Raza J, Smith CP, Miller WL, et al. Nonclassic congenital lipoid adrenal hyperplasia: a new disorder of the steroidogenic acute regulatory protein with very late presentation and normal male genitalia. J Clin Endocrinol Metab 2006;91:4781-5.

20. Metherell LA, Naville D, Halaby G, Begeot M, Huebner A, Nurnberg G, et al. Nonclassic lipoid congenital adrenal hyperplasia masquerading as familial glucocorticoid deficiency. J Clin Endocrinol Metab 2009;94:3865-71.

21. Sahakitrungruang T, Soccio RE, Lang-Muritano M, Walker JM, Achermann JC, Miller WL. Clinical, genetic, and functional characterization of four patients carrying partial loss-of-function mutations in the steroidogenic acute regulatory protein (StAR). J Clin Endocrinol Metab 2010;95:3352-9.

22. Fujieda K, Okuhara K, Abe S, Tajima T, Mukai T, Nakae J. Molecular pathogenesis of lipoid adrenal hyperplasia and adrenal hypoplasia congenita. J Steroid Biochem Mol Biol 2003;85:483-9.

23. Nakae J, Tajima T, Sugawara T, Arakane F, Hanaki K, Hotsubo T, et al. Analysis of the steroidogenic acute regulatory protein (StAR) gene in Japanese patients with congenital lipoid adrenal hyperplasia. Hum Mol Genet 1997;6:571-6.

24. Kim CJ. Congenital lipoid adrenal hyperplasia. Ann Pediatr Endocrinol Metab 2014;19:179-83.

25. Chen X, Baker BY, Abduljabbar MA, Miller WL. A genetic isolate of congenital lipoid adrenal hyperplasia with atypical clinical findings. J Clin Endocrinol Metab
2005;90:835-40.

26. Fluck CE, Maret A, Mallet D, Portrat-Doyen S, Achermann JC, Leheup B, et al. A novel mutation L260P of the steroidogenic acute regulatory protein gene in three unrelated patients of Swiss ancestry with congenital lipoid adrenal hyperplasia. J Clin Endocrinol Metab 2005;90:5304-8.

27. Lorence MC, Murry BA, Trant JM, Mason JI. Human 3 beta-hydroxysteroid dehydrogenase/delta $5 \rightarrow$ isomerase from placenta: expression in nonsteroidogenic cells of a protein that catalyzes the dehydrogenation/isomerization of C21 and C19 steroids. Endocrinology 1990;126:2493-8.

28. Lorence MC, Corbin CJ, Kamimura N, Mahendroo MS, Mason JI. Structural analysis of the gene encoding human 3 beta-hydroxysteroid dehydrogenase/delta $5 \rightarrow 4$-isomerase. Mol Endocrinol 1990;4:1850-5

29. Lachance Y, Luu-The V, Labrie C, Simard J, Dumont M, de Launoit Y, et al. Characterization of human 3 betahydroxysteroid dehydrogenase/delta 5-delta 4-isomerase gene and its expression in mammalian cells. J Biol Chem 1990;265:20469-75.

30. Bongiovanni AM. The adrenogenital syndrome with deficiency of 3 beta-hydroxysteroid dehydrogenase. J Clin Invest 1962;41:2086-92.

31. Simard J, Ricketts ML, Gingras S, Soucy P, Feltus FA, Melner MH. Molecular biology of the 3beta-hydroxysteroid dehydrogenase/delta5-delta4 isomerase gene family. Endocr Rev 2005;26:525-82.

32. Jeandron DD, Sahakitrungruang T. A novel homozygous Q334X mutation in the HSD3B2 gene causing classic $3 \beta$-hydroxysteroid dehydrogenase deficiency: an unexpected diagnosis after a positive newborn screen for 21-hydroxylase deficiency. Horm Res Paediatr 2012;77:3348.

33. Moisan AM, Ricketts ML, Tardy V, Desrochers M, Mébarki F, Chaussain JL, et al. New insight into the molecular basis of 3beta-hydroxysteroid dehydrogenase deficiency: identification of eight mutations in the HSD3B2 gene eleven patients from seven new families and comparison of the functional properties of twenty-five mutant enzymes. J Clin Endocrinol Metab 1999;84:4410-25.

34. Chang YT, Kulin HE, Garibaldi L, Suriano MJ, Bracki K, Pang S. Hypothalamic-pituitary-gonadal axis function in pubertal male and female siblings with glucocorticoidtreated nonsalt-wasting 3 beta-hydroxysteroid dehydrogenase deficiency congenital adrenal hyperplasia. J Clin Endocrinol Metab 1993;77:1251-7.

35. Sanchez R, Rheaume E, Laflamme N, Rosenfield RL, Labrie F, Simard J. Detection and functional characterization of the novel missense mutation Y254D in type II 3 betahydroxysteroid dehydrogenase ( 3 beta HSD) gene of a female patient with nonsalt-losing 3 beta HSD deficiency. J Clin Endocrinol Metab 1994;78:561-7.

36. Mermejo LM, Elias LL, Marui S, Moreira AC, Mendonca $\mathrm{BB}$, de Castro M. Refining hormonal diagnosis of type II 
3beta-hydroxysteroid dehydrogenase deficiency in patients with premature pubarche and hirsutism based on HSD3B2 genotyping. J Clin Endocrinol Metab 2005;90:1287-93.

37. Peter M, Janzen N, Sander S, Korsch E, Riepe FG, Sander J. A case of 11 beta-hydroxylase deficiency detected in a newborn screening program by second-tier LC-MS/MS. Horm Res 2008;69:253-6.

38. White PC, Dupont J, New MI, Leiberman E, Hochberg Z, Rosler A. A mutation in CYP11B1 (Arg-448----His) associated with steroid 11 beta-hydroxylase deficiency in Jews of Moroccan origin. J Clin Invest 1991;87:1664-7.

39. Nimkarn S, New MI. Steroid 11 beta-hydroxylase deficiency congenital adrenal hyperplasia. Trends Endocrinol Metab 2008;19:96-9.

40. Zhu YS, Cordero JJ, Can S, Cai LQ, You X, Herrera C, et al. Mutations in CYP11B1 gene: phenotype-genotype correlations. Am J Med Genet A 2003;122A:193-200.

41. Joehrer K, Geley S, Strasser-Wozak EM, Azziz R, Wollmann HA, Schmitt K, et al. CYP11B1 mutations causing nonclassic adrenal hyperplasia due to 11 beta-hydroxylase deficiency. Hum Mol Genet 1997;6:1829-34.

42. Reisch N, Hogler W, Parajes S, Rose IT, Dhir V, Gotzinger J, et al. A diagnosis not to be missed: nonclassic steroid $11 \beta$-hydroxylase deficiency presenting with premature adrenarche and hirsutism. J Clin Endocrinol Metab 2013;98:E1620-5.

43. Hampf M, Dao NT, Hoan NT, Bernhardt R. Unequal crossing-over between aldosterone synthase and 11 betahydroxylase genes causes congenital adrenal hyperplasia. J Clin Endocrinol Metab 2001;86:4445-52.

44. Chung BC, Picado-Leonard J, Haniu M, Bienkowski M, Hall PF, Shively JE, et al. Cytochrome P450c17 (steroid 17 alpha-hydroxylase/17,20 lyase): cloning of human adrenal and testis cDNAs indicates the same gene is expressed in both tissues. Proc Natl Acad Sci U S A 1987;84:407-11.

45. Picado-Leonard J, Miller WL. Cloning and sequence of the human gene for P450c17 (steroid 17 alphahydroxylase/17,20 lyase): similarity with the gene for P450c21. DNA 1987;6:439-48.

46. Sahakitrungruang T, Tee MK, Speiser PW, Miller WL. Novel P450c17 mutation H373D causing combined 17alphahydroxylase/17,20-lyase deficiency. J Clin Endocrinol
Metab 2009;94:3089-92.

47. Geller DH, Auchus RJ, Mendonca BB, Miller WL. The genetic and functional basis of isolated 17,20-lyase deficiency. Nat Genet 1997;17:201-5.

48. Sherbet DP, Tiosano D, Kwist KM, Hochberg Z, Auchus RJ. CYP17 mutation E305G causes isolated 17,20-lyase deficiency by selectively altering substrate binding. J Biol Chem 2003;278:48563-9.

49. Fluck CE, Tajima T, Pandey AV, Arlt W, Okuhara K, Verge $\mathrm{CF}$, et al. Mutant P450 oxidoreductase causes disordered steroidogenesis with and without Antley-Bixler syndrome. Nat Genet 2004;36:228-30.

50. Scott RR, Miller WL. Genetic and clinical features of p450 oxidoreductase deficiency. Horm Res 2008;69:266-75.

51. Sahakitrungruang T, Huang N, Tee MK, Agrawal V, Russell WE, Crock P, et al. Clinical, genetic, and enzymatic characterization of P450 oxidoreductase deficiency in four patients. J Clin Endocrinol Metab 2009;94:4992-5000.

52. Hershkovitz E, Parvari R, Wudy SA, Hartmann MF, Gomes LG, Loewental N, et al. Homozygous mutation G539R in the gene for P450 oxidoreductase in a family previously diagnosed as having 17,20-lyase deficiency. J Clin Endocrinol Metab 2008;93:3584-8.

53. Arlt W, Walker EA, Draper N, Ivison HE, Ride JP, Hammer F, et al. Congenital adrenal hyperplasia caused by mutant P450 oxidoreductase and human androgen synthesis: analytical study. Lancet 2004;363:2128-35.

54. Huang N, Pandey AV, Agrawal V, Reardon W, Lapunzina PD, Mowat D, et al. Diversity and function of mutations in p450 oxidoreductase in patients with Antley-Bixler syndrome and disordered steroidogenesis. Am J Hum Genet 2005;76:729-49.

55. Fukami M, Nishimura G, Homma K, Nagai T, Hanaki $\mathrm{K}$, Uematsu A, et al. Cytochrome P450 oxidoreductase deficiency: identification and characterization of biallelic mutations and genotype-phenotype correlations in 35 Japanese patients. J Clin Endocrinol Metab 2009;94:172331.

56. Krone N, Reisch N, Idkowiak J, Dhir V, Ivison HE, Hughes $\mathrm{BA}$, et al. Genotype-phenotype analysis in congenital adrenal hyperplasia due to P450 oxidoreductase deficiency. J Clin Endocrinol Metab 2012;97:E257-67. 